\title{
Unilateral Hypoplastic Kidney in a Case of Holt-Oram Syndrome
}

\author{
Dasgupta MK' ${ }^{1}$, Dutta $\mathrm{A}^{2}$, Sarkar $\mathbf{S}^{3}$, Patra $\mathrm{C}^{4}$, Dey $\mathrm{C}^{5}$ \\ ${ }^{1} \mathrm{Dr}$. Malay Kumar Dasgupta, MBBS, DCH, MD, \\ Professor, ${ }^{2}$ Dr. Abhijit Dutta, MBBS, MD, Assistant \\ Professor, ${ }^{3} \mathrm{Dr}$. Shatanik Sarkar, MBBS. Post Graduate \\ Trainee in Paediatrics, ${ }^{4}$ Dr. Chaitali Patra, MBBS, Post \\ Graduate Trainee in Paediatrics, ${ }^{5} \mathrm{Dr}$. Chandrashekhar \\ Dey, MBBS. Post Graduate Trainee in Paediatrics. All \\ from the Department of Paediatric Medicine, R.G. Kar \\ Medical College and Hospital, Kolkata, India.
}

\section{Introduction}

olt-Oram syndrome (HOS) is characterised by I skeletal abnormalities of the upper limb with mild to severe congenital cardiac defects. It has autosomal dominant inheritance and near complete penetrance with variable expression ${ }^{1}$. A mutation in TBX5 gene located on chromosome 12 (12q24.1) has been associated with variable phenotypes ${ }^{2,3}$. This syndrome, first described in $1960^{1}$, is also referred to as Hand-Heart syndrome. About 350 cases have been reported worldwide and some of them were associated with other anomalies. We find it interesting to present this case since there is no reported case of Holt-Oram Syndrome associated with unilateral hypoplastic kidney.

\section{The Case}

A one-day-old, $2.4 \mathrm{~kg}$, Hindu male baby, born out of non consanguineous marriage \& delivered normally of a 25-year-old mother, was admitted in our nursery with several congenital anomalies of the upper limbs. The baby had radially curved \& short left forearm with absent thumb, index \& middle fingers of the left hand and hypoplastic thumb attached to the palm by a thin thread-like pedicle in the right one [Figure 1]. Other anthropometric parameters were within normal limits. There was no facial dysmorphism. Thorough systemic examination didn't reveal any abnormality.

X-ray of upper limbs showed absent radius with absent $1^{\text {st }}, 2^{\text {nd }}$ and $3^{\text {rd }}$ metacarpal in left side and absent $1^{\text {st }}$ metacarpal on the right side. Remaining skeletal

\author{
Address for correspondence \\ Dr. Shatanik Sarkar \\ Address: Block-B, Flat No. 304, DB-24, \\ Deshbandhunagar, Baguiati, Kolkata - 700059. \\ E-mail: baselinegame@gmail.com
}

\begin{abstract}
Holt-Oram syndrome (HOS) is characterised by skeletal abnormalities of the upper limb \& congenital cardiac defects. Here we report a case of one day old male baby with skeletal abnormalities of forearms and hands, atrial septal defect of ostium secundum type and unilateral hypoplastic kidney. Till date, other associated anomalies like extra-hepatic portal hypertension, renal artery malformations etc have been reported with Holt-Oram syndrome, but it is the first case to be reported in association with hypoplastic kidney.
\end{abstract}

Key words: Holt-Oram Syndrome, Ultrasonography, Hypoplastic kidney.

survey did not reveal any abnormality. Hemogram, renal function and serum electrolytes were normal. ECG was normal. Echocardiography showed ostium secundum ASD (6.4mm in size). Abdominal ultrasongraphy showed hypoplastic kidney in the right side $(1.53 \mathrm{cc})$ with normal volume of left one $(4.36 \mathrm{cc})$ [Figure 2].

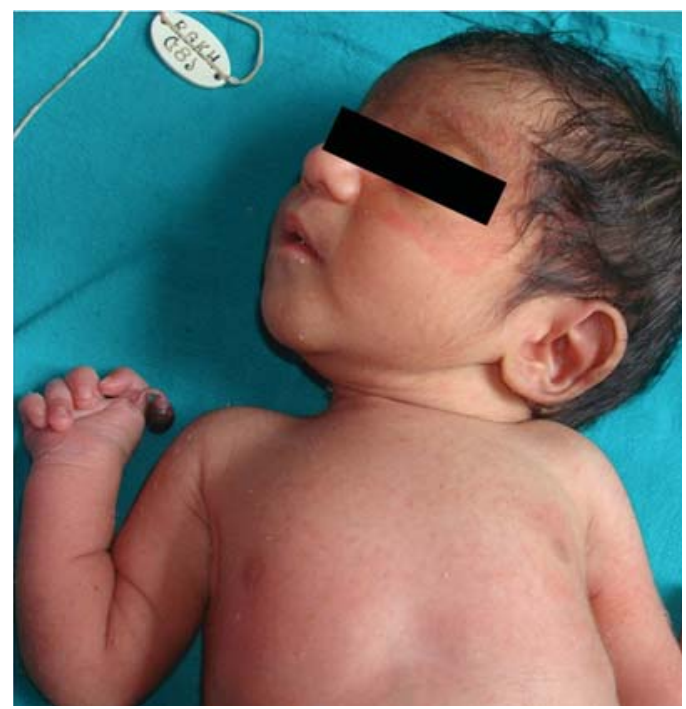

Fig 1: Picture of the baby showing radially curved and short left forearm with absent thumb, index \& middle fingers of the left hand with hypoplastic thumb attached to the palm by thin thread-like pedicle in the right one.

\section{How to cite this article ?}

Dasgupta MK, Dutta A, Sarkar S, Patra C, Dey C. Unilateral Hypoplastic Kidney in a Case of Holt-Oram Syndrome. J Nepal Paediatr Soc 2013;33(1):77-79. 


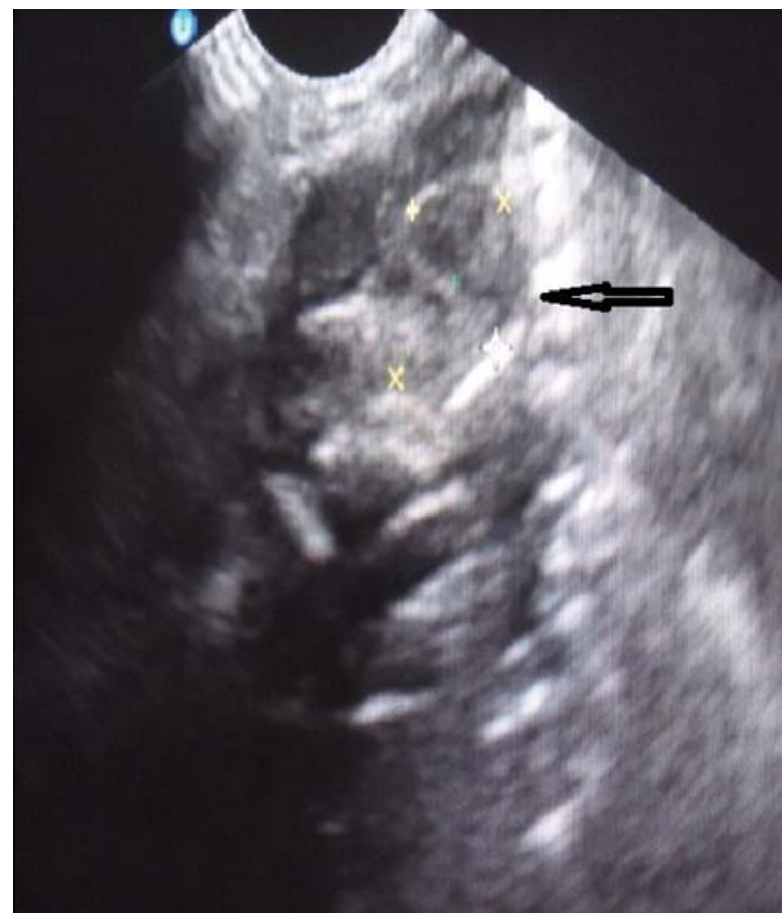

Fig 2: Abdominal ultrasonography showing hypoplastic kidney in the right side (Volume:1.53cc).

\section{Discussion}

Holt-oram syndrome is a rare genetic disorder. Its prevalence is calculated as 0.95 in $1,00,000$ births. It is characterised by skeletal dysplasia of upper limb and congenital cardiac malformation. The responsible gene is reported to be localized in long arm of chromosome 12 (12q24.1) which encodes human transcription factor TBX52. Mutation of the gene produces abnormal expression of the limb and cardiac development. It has autosomal dominant inheritance. Forty percent of cases are associated with new mutations.

Upper extremity abnormalities may be unilateral or bilateral, but left side is mostly involved like our case. These abnormalities are ranging from mild hypoplasia of radius or ulna to phocomelia ${ }^{3}$. This baby had absence of thumb, index \& middle fingers of the left hand with hypoplastic thumb on the right side.

Secundum-type atrial septal defect (ASD) and ventricular septal defect (VSD) are the most common heart defects. Other cardiac anomalies are conduction defect, truncus arteriosus, mitral valve defect, patent ductus arteriosus, tetralogy of Fallot, persistent left superior vena cava, abnormal left coronary artery ostium, atrioventricular canal defect and hypoplastic left heart ${ }^{4,5,6,7}$. In our case, ostium secundum ASD was present.

Differential diagnosis considered in the present case was Fanconi anaemia (FA), Thrombocytopenia - absent radius (TAR) syndrome, VATER / VACTERL syndrome \& Trisomy 18. Fanconi anaemia had been excluded as there were no characteristic physical malformations or hematologic manifestations in this baby $^{8}$. In TAR, in which radii are absent, the thumbs are always present, not so for our case. It presents at birth with severe thrombocytopenia with bleeding manifestations and radial ray defects ${ }^{9}$. Trisomy 18 can rarely have radial ray defects and eye anomalies. However trisomy 18 has host of different physical abnormalities and a typical facies ${ }^{8}$. Holt-oram syndrome has considerable overlap in the physical abnormalities with VATER /VACTERL syndromes, but the present case had no vertebral anomaly though there was hypoplastic kidney in the right side.

In literature there is a case report of ectopic kidney with radial dysplasia only ${ }^{10}$. Holt-oram syndrome with extrahepatic portal hypertension and renal artery malformation has been reported previously ${ }^{11}$, but no report associated with hypoplastic kidney has been done till date.

\section{Conclusion}

Holt-oram syndrome itself is a rare syndrome and among all the previously reported cases, none of them was associated with hypoplastic kidney. Thus, USG abdomen may be considered as a screening investigation in patients with Holt-oram syndrome to rule out this association and thereby to prevent its future complications.

\section{References}

1. Holt M, Oram S. Familial heart disease with skeletal malformations. Br Heart J 1960;22(2):236-42.

2. Bohm J, Heinritz W, Craig A, Vujic M, EkmanJoelsson BM, Kohlhase J, et al. Functional analysis of the novel TBX5 c.1333delC mutation resulting in an extended TBX5 protein. BMC Med Genet 2008;9:88.

3. Basson CT, Huang $T$, Lin RC, Bachinsky DR, Weremowicz S, Vaglio A, et al. Different TBX5 interactions in heart and limb defined by Holt-Oram syndrome mutations. Proc Natl Acad Sci USA 1999;96(6):2919-24.

4. Bruneau BG, Logan M, Davis N, et al.: Chamberspecific cardiac expression of Tbx5 and heart defects in Holt-Oram syndrome. Dev Biol 1999;211:100-8

5. Brockhoff CJ, Kober H, Tsilimingas F, Dapper F, Münzel T, Meinertz T. Holt-Oram syndrome. Circulation 1999;99:1395-6.

6. Zhang KZ, Sun QB, Cheng TO. Holt-Oram syndrome in China: A collective review of 18 cases. A Heart J 1986;111:572-7. 
7. Glauser TA, Zackai E, Weinberg P, et al. Holt-Oram syndrome associated with the hypoplastic left heart syndrome. Clin Genet 1989;36:69-72.

8. Alter BP, Young NS. The bone marrow failure syndromes. In: Nathan DG, Orkin SH (Eds.):Nathan and Oski's Hematology of infancy and childhood, 5th edn., WB Saunders, Philadelphia. 1998; pp. 259-72.
9. Jones KL. Thrombocytopenia - absent radius syndrome. In: Jones KL (Ed.) Smith's Recognizable Patterns of Human Malformations, Philadelphia; WB Saunders Company,5th edn, 1997; pp. 322-3.

10. Kamran Afzal,M. Najmussaqib: Familial Radial Dyplasia with Renal Ectopia. Indian Pediatr 2006;43:76-7

11. Koutlas ED, Papageorgiou AA, Athyros VG: HoltOram syndrome with malformations of renal and cerebral arteries. Acta Cardiol 1996;51:373-6. 